\title{
Molecular Characterization of Maize (Zea mays L.) Inbred Lines using Simple Sequence Repeats (SSR) Marker
}

\author{
Urusha Zareen ${ }^{1}$, Birender Singh ${ }^{1 *}$, Bishun Deo Prasad ${ }^{2}$, S. S. Mandal', \\ R. B. P. Nirala ${ }^{1}$ and Girish Nandan ${ }^{1}$ \\ ${ }^{1}$ Department of Plant Breeding and Genetics, ${ }^{2}$ Department of Molecular Biology and Genetic \\ Engineering, Bihar Agricultural University, Sabour, Bhagalpur-813210, India \\ *Corresponding author
}

\section{A B S T R A C T}

\section{Keywords}

Maize, Zea mays, SSR marker, PIC, UGPMA

\section{Article Info}

Accepted:

23 May 2020

Available Online:

10 June 2020
Genomic DNA was isolated by CTAB method and then subjected to PCR amplification by using 22 SSR primers. Among 22 primers, 17 primers were amplified. The PIC values were ranged from 0.46 (Phi046) which is the minimum value to 0.81 (Phi059) which is the highest value. The frequencies of alleles were ranged from 0.01 to 0.07 . By the use of Unweighted Paired Group Method (UGPMA) for cluster analysis and formed two cluster. DHM117 showed 65per cent similarity with CLQRCY44 and CLO2450 showed 3per cent similarity with BML-6 which is the minimum value. In this study, PIC value indicated a good efficiency of marker for studying the polymorphism level available in studied inbred line and it also indicated their suitability for further breeding programs.

\section{Introduction}

Maize (Zea mays L., 2n=20) in America and India is referred to as corn which literally mean "that which sustains life" (Akinyele and Adigum, 2006). It belongs to gramineae family. It is the third most important crop in India after rice and wheat. It is grown worldwide in a wider range of environments because of its greater adaptability (Kogbe and Adediran, 2003). Globally, maize is known as Queen of cereals because it has highest genetic yield potential among the cereals. Grain provides food items which are consumed in the form of starch which accounts 14per cent, corn flakes also glucose.

It is also used as animal feed in poultry which accounts 47per cent and it is the most important use and demand of maize. Farmers can easily shield the deteriorating grade of soil by growing the maize which preserves 90per cent of water and 70per cent of potency and it is more profit than wheat and paddy in 
production. Simple Sequence Repeat (SSR) marker also known as microsatellites. It is a random repeated motifs of 1-6 nucleotides present in all eukaryotic and prokaryotic genomes and coding and non-coding nuclear and organeller DNA (Zane et al., 2002). In maize breeding programmes this markers with a polymorphism based on different number of repeated motifs at a given locus are becoming a marker choice (Inghelandt et al., 2018, Kumari et al., 2018).

This marker became the choice for fingerprinting purposes in many plant species due to their high polymorphism, co dominancy and reproducibility and stability of results and in addition to their usefulness in mapping and breeding (Gupta and Varshney, 2000).

Because of the high variability in the number of repeat units it is widely used in many areas of crop improvement. SSR markers are useful tool to explore the molecular diversity among the maize genotypes, as they are not influenced by the environment which can help breeders for selection of diverse parental line which is useful for hybridization programme in heterosis breeding for maize yield improvement.

It can be used for mapping locations within the genome specifically in genetic linkage analysis to locate a gene or a mutation responsible for a given trait or disease. It can also be used for studies of gene duplication or deletion.

\section{Materials and Methods}

$0.5 \mathrm{gm}$ of leaf sample was cut into small bits with the help of sterile scissors and grinded with $2 \mathrm{ml}$ of hot $\left(65^{\circ} \mathrm{C}\right) \mathrm{CTAB}$ extraction buffer in mortar and pestle. Then transfer $600 \mu l$ of extract into eppendorf tube. Incubate the tube on water bath at $65^{\circ} \mathrm{C}$ for 45 minutes with occasional mixing. After 45 minutes the tubes were removed from the water bath and equal volume of Chloroform : Isoamyl alcohol mixture (24:1 v/v) was added and mix gently by inversion.

Then centrifuge at $12,000 \mathrm{rpm}$ for $5 \mathrm{~min}$ at room temperature. The clear aqueous phase was transferred to a new eppendorf tube. Add $2 / 3^{\text {rd }}$ volume of chilled isopropanol and mix gently by inversion and incubate on ice bath for 30 minutes.

Then it was centrifuge at $12,000 \mathrm{rpm}$ for 15 minutes at room temperature. Supernatant was discarded and DNA pellet was washed with 70per cent ethanol $(200 \mu l)$. Then centrifuge at $12,000 \mathrm{rpm}$ for 10 minutes at room temperature. The alcohol was decanted and DNA pellet was air dried. Then lastly,

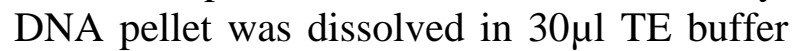
(0.1) and stored at $-20^{\circ} \mathrm{C}$.

DNA was diluted and subjected to PCR amplification by using the 22 SSR primers (Table 1). Firstly the cocktail were prepared in the pcr tube using $2.0 \mu \mathrm{l}$ of template DNA, $5.9 \mu \mathrm{l}$ milliQ water, $1 \mu \mathrm{l}$ of PCR buffer with $1.5 \mathrm{mM} \mathrm{MgCl} 2,0.2 \mu \mathrm{l}$ of $\mathrm{dNTP}_{\mathrm{s}}, 0.2 \mu \mathrm{L}$ of Forward primer and $0.2 \mu \mathrm{l}$ of reverse primer, $0.5 \mu$ of Taq DNA polymerase for PCR amplification.

The reaction mixture was short spin then the PCR tubes were loaded on automated thermal cycler. The steps used in PCR reaction were as follows:

$94^{\circ} \mathrm{C}$ for $5 \mathrm{~min}$

$94^{\circ} \mathrm{C}$ for $1 \mathrm{~min}$

$53-48^{\circ} \mathrm{C}$ for $30 \mathrm{sec}$

$72^{\circ} \mathrm{C}$ for $40 \mathrm{sec}$

$94^{\circ} \mathrm{C}$ for $1 \mathrm{~min}$

$48^{\circ} \mathrm{C}$ for $30 \mathrm{sec}$

$72^{\circ} \mathrm{C}$ for $45 \mathrm{sec}$

$72^{\circ} \mathrm{C}$ for $5 \mathrm{~min}$ 


\section{Data analysis and scoring}

The amplified bands were scored on the basis of presence or absence of bands where presence of bands were donated by 1 and absence were denoted by 0 . The PIC (Polymorphic information was calculated using Power Marker 3.5. Coefficients of similarity were calculated by using Jaccard's similarity coefficient by SIMQUAL function and cluster analysis was performed by agglomerative technique using the UPGMA (Unweighted Pair Group Method with Arithmetic mean) method by SAHN clustering function of NTSYS-pc version 2.02 (Rohlf, 1994).

\section{Results and Discussion}

Analysis of all the 14 SSR primer which show polymorphism across the 10 inbred lines. A total no. of 53 alleles was amplified. The PIC value ranged from 0.46 (Phi046) to 0.81 (Phi059) with an average of 0.76 .

The SSR analysis showed maximum genetic similarity between CLQRCY 44 and DHM 117 (0.65) and minimum genetic similarity between CLO2450 and BML-6 (0.03) (Fig.1-7 and Table 2).

Table.1 List of genotypes taken for the study

\begin{tabular}{|l|l|}
\hline Serial no. & Genotype \\
\hline $\mathbf{1}$ & LM-14 \\
\hline $\mathbf{2}$ & CLO2450 \\
\hline $\mathbf{3}$ & SML-1 \\
\hline $\mathbf{4}$ & LM-13 \\
\hline $\mathbf{5}$ & CML-451 \\
\hline $\mathbf{6}$ & BML-6 \\
\hline $\mathbf{7}$ & BML-7 \\
\hline $\mathbf{8}$ & CLQRCY-44 \\
\hline $\mathbf{9}$ & DHM-117 \\
\hline $\mathbf{1 0}$ & PAC-740 \\
\hline
\end{tabular}

Table.2 List of primers and their PIC value

\begin{tabular}{|l|l|c|c|}
\hline S.No. & Primer code & Freq. & PIC value \\
\hline 1. & Phi 006 & 0.04 & 0.64 \\
& Phi006 & 0.04 & \\
\hline 2. & Phi006 & 0.02 & \\
& Phi059 & 0.03 & $\mathbf{0 . 8 1}$ \\
& Phi059 & 0.03 & \\
\hline 3. & Phi059 & 0.03 & \\
\hline & Phi063 & 0.06 & 0.48 \\
\hline 4. & Phi063 & 0.04 & \\
& Phi062 & 0.04 & \\
& Phi062 & 0.05 & 0.58 \\
\hline & Phi062 & 0.01 & \\
\hline
\end{tabular}




\begin{tabular}{|c|c|c|c|}
\hline 5. & $\begin{array}{l}\text { Phi065 } \\
\text { Phi065 } \\
\text { Phi065 }\end{array}$ & $\begin{array}{l}0.02 \\
0.04 \\
0.04\end{array}$ & 0.64 \\
\hline 6. & $\begin{array}{l}\text { Phi050 } \\
\text { Phi050 } \\
\text { Phi050 }\end{array}$ & $\begin{array}{l}0.03 \\
0.02 \\
0.05\end{array}$ & 0.62 \\
\hline 7. & $\begin{array}{l}\mathrm{Nc130} \\
\mathrm{Nc} 130 \\
\mathrm{Nc} 130 \\
\mathrm{Nc} 130\end{array}$ & $\begin{array}{l}0.02 \\
0.02 \\
0.03 \\
0.03\end{array}$ & 0.74 \\
\hline 8. & $\begin{array}{l}\text { Phi032 } \\
\text { Phi032 } \\
\text { Phi032 } \\
\text { Phi032 } \\
\text { Phi032 }\end{array}$ & $\begin{array}{l}0.03 \\
0.02 \\
0.01 \\
0.02 \\
0.02\end{array}$ & 0.78 \\
\hline 9. & $\begin{array}{l}\text { Phi064 } \\
\text { Phi064 } \\
\text { Phi064 } \\
\text { Phi064 }\end{array}$ & $\begin{array}{l}0.04 \\
0.04 \\
0.02 \\
0.02\end{array}$ & 0.72 \\
\hline 10. & $\begin{array}{l}\text { Phi034 } \\
\text { Phi034 } \\
\text { Phi034 }\end{array}$ & $\begin{array}{l}0.03 \\
0.02 \\
0.05\end{array}$ & 0.62 \\
\hline 11. & $\begin{array}{l}\text { Phi014 } \\
\text { Phi014 } \\
\text { phi014 }\end{array}$ & $\begin{array}{l}0.03 \\
0.04 \\
0.03\end{array}$ & 0.66 \\
\hline 12. & $\begin{array}{l}\text { Phi073 } \\
\text { Phi073 } \\
\text { Phi073 }\end{array}$ & $\begin{array}{l}0.03 \\
0.03 \\
0.04\end{array}$ & 0.66 \\
\hline 13. & $\begin{array}{l}\text { Phi011 } \\
\text { Phi011 }\end{array}$ & $\begin{array}{l}0.04 \\
0.06\end{array}$ & 0.48 \\
\hline 14. & $\begin{array}{l}\text { Phi053 } \\
\text { Phi053 }\end{array}$ & $\begin{array}{l}0.04 \\
0.06\end{array}$ & 0.48 \\
\hline 15. & $\begin{array}{l}\text { Phi024 } \\
\text { Phi024 } \\
\text { Phi024 }\end{array}$ & $\begin{array}{l}0.02 \\
0.02 \\
0.06\end{array}$ & 0.56 \\
\hline 16. & $\begin{array}{l}\text { Bnlg391 } \\
\text { Bnlg391 } \\
\text { Bnlg391 } \\
\text { Bnlg391 }\end{array}$ & $\begin{array}{l}0.02 \\
0.01 \\
0.03 \\
0.04\end{array}$ & 0.70 \\
\hline 17. & $\begin{array}{l}\text { phi046 } \\
\text { Phi046 } \\
\text { phi046 }\end{array}$ & $\begin{array}{l}0.07 \\
0.02 \\
0.01\end{array}$ & 0.46 \\
\hline
\end{tabular}




\begin{tabular}{|l|l|l|l|l|l|l|l|l|l|l|}
\hline & LM14 & CLO2450 & SML1 & LM13 & CML451 & BML6 & BML7 & CLQRCY44 & DHM117 & PAC740 \\
\hline LM14 & 1 & 0.269 & 0.148 & 0.214 & 0.138 & 0.129 & 0.062 & 0.097 & 0.1 & 0.062 \\
\hline CLO2450 & & 1 & 0.2 & 0.138 & 0.185 & 0.03 & 0.1 & 0.065 & 0.067 & 0.138 \\
\hline SML1 & & & 1 & 0.107 & 0.111 & 0.067 & 0.148 & 0.148 & 0.154 & 0.069 \\
\hline LM13 & & & & 1 & 0.222 & 0.207 & 0.172 & 0.133 & 0.065 & 0.097 \\
\hline CML451 & & & & & 1 & 0.133 & 0.222 & 0.138 & 0.067 & 0.222 \\
\hline BML6 & & & & & & 1 & 0.4 & 0.346 & 0.308 & 0.167 \\
\hline BML7 & & & & & & & 1 & 0.545 & 0.375 & 0.214 \\
\hline CLQRCY44 & & & & & & & & 1 & 0.65 & 0.308 \\
\hline DHM117 & & & & & & & & & 1 & 0.435 \\
\hline PAC740 & & & & & & & & & & 1 \\
\hline
\end{tabular}

Fig.1 Similarity matrix for Jaccard's coefficient for 10 maize genotypes based on SSR analysis

The UPGMA based dendrogram of 10 inbreds lines separated into two well defined groups.

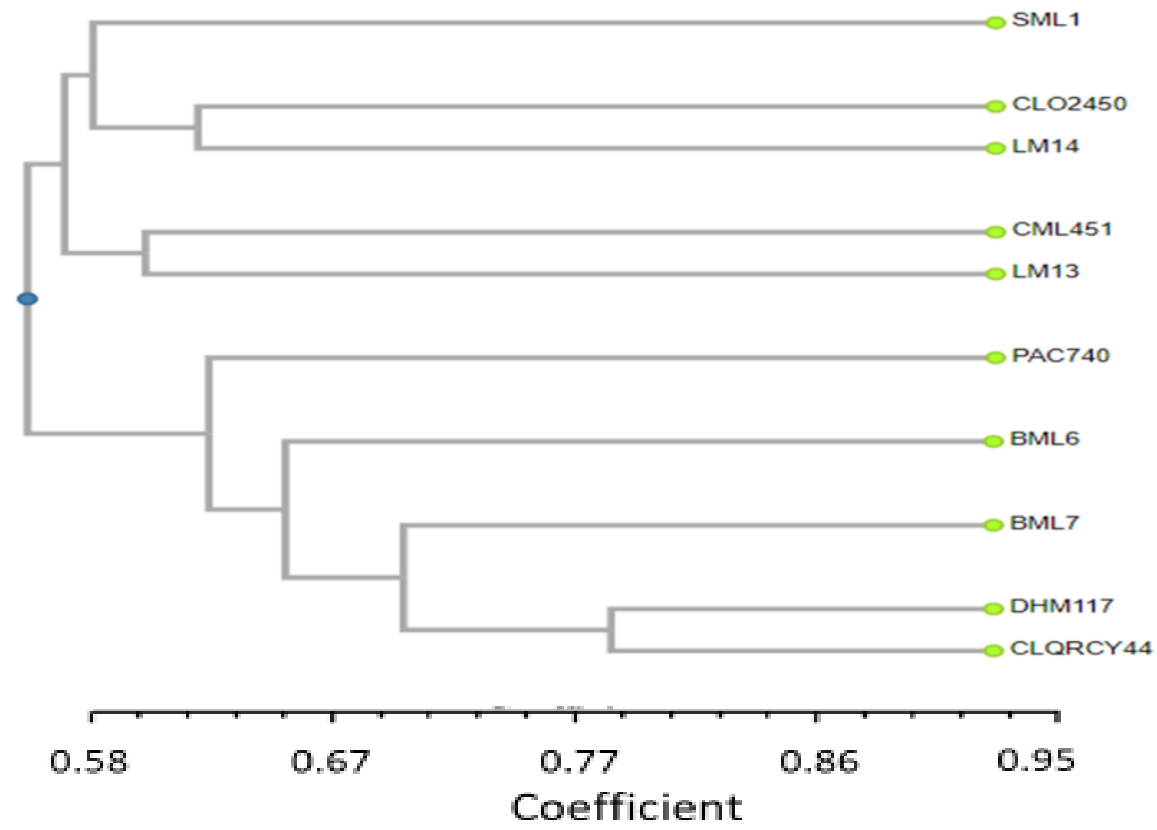

Fig.2 UPGMA based cluster analysis of 10 maize inbred lines using SSR markers. It was supported by Patel et al., (2017)

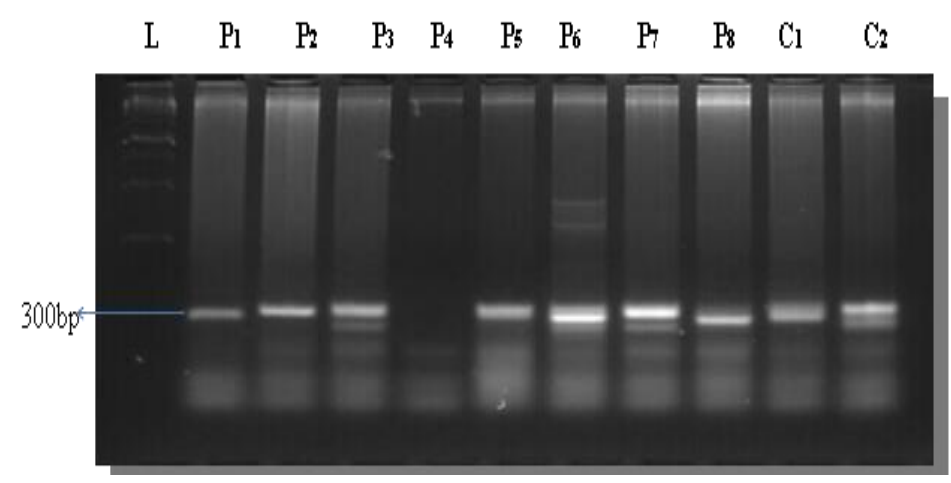

Fig.3 Phi006 SSR marker 


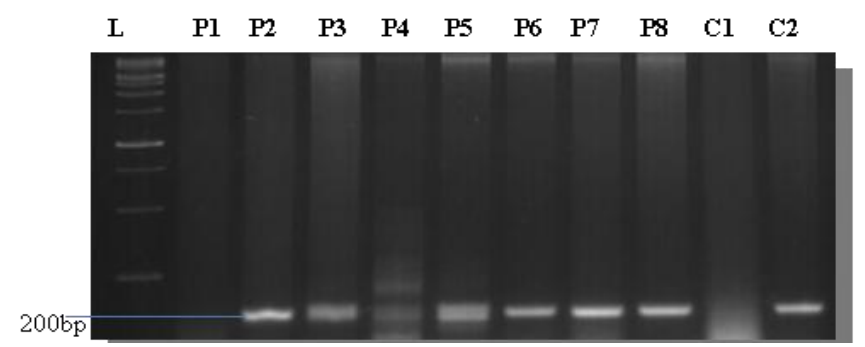

Fig.4 Phi059 SSR marker

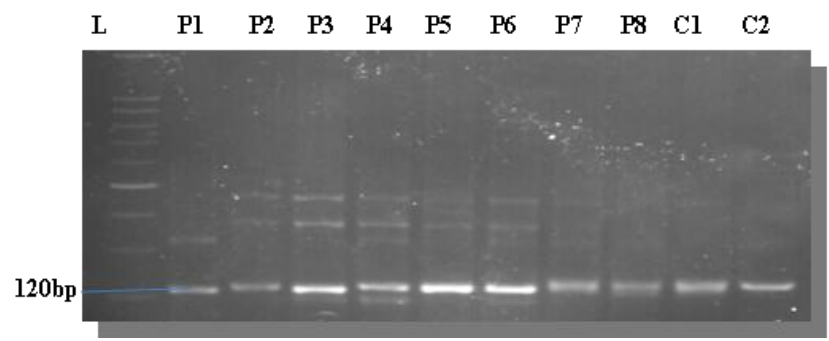

Fig.5 Phi062 SSR Marker

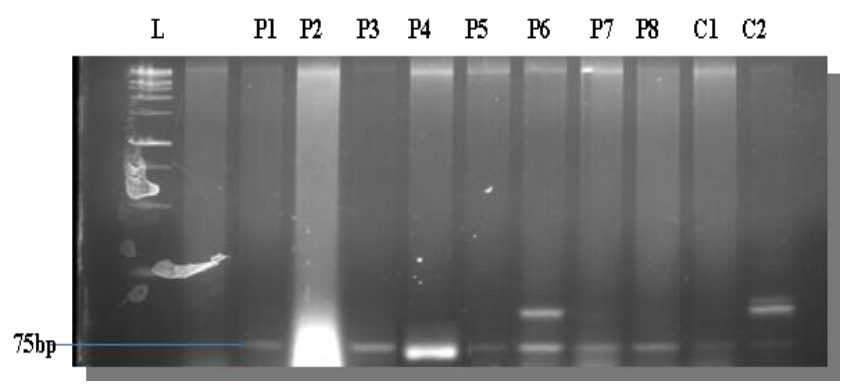

Fig.6 Phi063 SSR marker

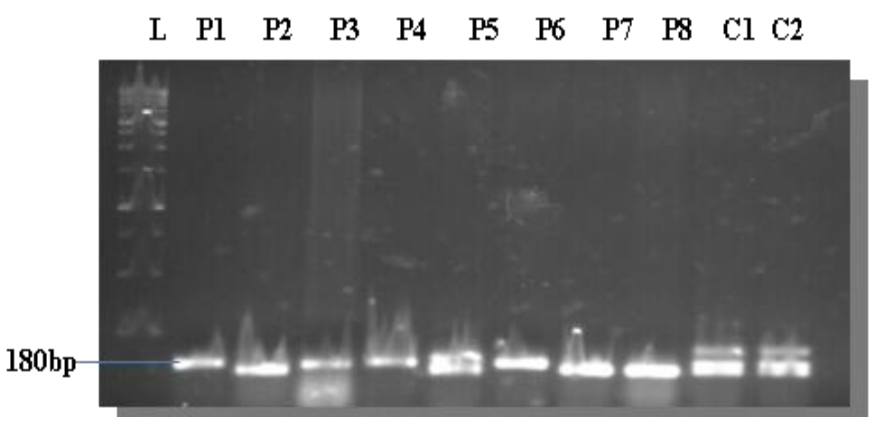

Fig.7 Phi065 SSR marker

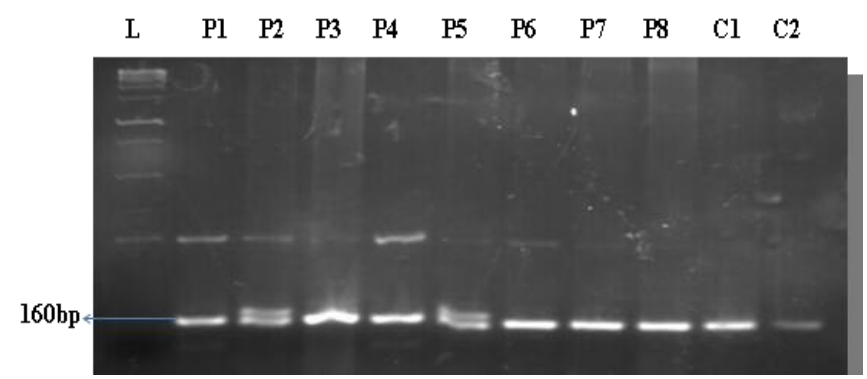

Fig.8 Phi050 SSR marker 
SSR markers have been increasingly used as efficient tools to determine genetic diversity and relationship among maize inbred lines. In this study, PIC value indicated a good efficiency of markers for studying the polymorphism level available in studied inbred lines. High level of diversity among the inbreds detected with SSR markers indicated their suitability for further breeding programs.

\section{Acknowledgement}

The authors acknowledge all the support given by the Molecular biology and Genetic Engineering Laboratory and other concerned departments, Bihar Agricultural University, Sabour, Bhagalpur, Bihar.

\section{References}

Doyle JJ, Doyle JL (1990) Isolation of plant DNA from fresh tissue. BRL Focus. 12:13-15.

Jambrovic A, D Simic, $\mathrm{T}$ Ledencan, $\mathrm{Z}$ Zdunic, I Brkic (2008) Genetic diversity among maize (Zea mays L.) inbred lines in Eastern Croatia. Period BioScience. 110: 251-255.

Zane, L., L Bargelloni, T Patarnello (2002) Strategies for microsatellite isolation. Molecular Ecology. 11: 1-16.

Maniruzzamzn Azam M G, Islam S, Hossain
MG, Rohman MM (2018). Molecular assessment of maize inbred lines (Zea mays L.) using microsatellite markers. Bangladesh Journal Agricultural Research. 43(4): 533-542.

Patel Keyur A, Khanorkar SM, Damor Azadchandra S, Parmar, HitikshaK (2017). Microsatellite based molecular characterization and genetic diversity analysis of maize (Zea mays L.) inbred lines. 10(6): 773-777.

PK Gupta, RK Varshney (2000). The development and use of microsatellite markers for genetic analysis and plant breeding with emphasis on bread wheat. Euphytica. 113(3): 163-185.

Sharma T, Kumar A, Dwivedi SC, Vyas RP (2017). Molecular characterization and genetic diversity analysis of selected maize inbreds using SSR markers. Journal of environmental biology. 39: 228-236.

Shehata AfafI, GhetharHaila A, AlHomaidan Ali, A. (2009). Application of simple sequence repeat (SSR) markers for molecular diversity and heterozygosity analysis in maize inbred lines. Saudi Journal of Biological Science. 16 (2): 57-62.

Shiri Mohammadreza (2011). Identification of informative simple sequence repeat (SSR) markers for drought tolerance in maize.

\section{How to cite this article:}

Urusha Zareen, Birender Singh, Bishun Deo Prasad, S. S. Mandal, R. B. P. Nirala and Girish Nandan. 2020. Molecular Characterization of Maize (Zea mays L.) Inbred Lines using Simple Sequence Repeats (SSR) Marker. Int.J.Curr.Microbiol.App.Sci. 9(06): 3158-3164. doi: https://doi.org/10.20546/ijcmas.2020.906.378 